\title{
CLINICAL STUDIES OF THE RESPIRATION
}

\author{
IV. THE VITAL CAPACITY OF THE LUNGS AND ITS RELATION TO DYSPNEA*
}

FRANCIS W. PEABODY, M.D., and JOHN A. WENTWORTH, M.D. BOSTON

\section{INTRODUCTION}

In an earlier paper ${ }^{1}$ in this series, observations were described on the production of dyspnea in normal subjects and in patients with cardiac disease by means of increasing amounts of carbon dioxid in the inspired air. It was found that patients with heart disease became dyspneic more easily than did healthy subjects, and this tendency seemed to depend largely on their inability to increase the depth of respiration in a normal manner. A few preliminary determinations showed that this inability to breathe deeply corresponded to a diminished vital capacity of the lungs as measured by the volume of the greatest possible expiration after the deepest inspiration. Since any condition which limits the possibility of increasing the minute-volume of air breathed must be an important factor in the production of dyspnea, it appeared worth while to undertake an extensive study of the vital capacity of the lungs in those diseases in which dyspnea is a frequent symptom. The present paper deals with observations on the vital capacity in a large series of normal persons, of patients with heart disease and of patients with various other clinical conditions. Particular attention has been paid to the findings in cardiac disease because they appear to be of some practical significance. The results reported indicate that there is a very close parallelism between a decrease in the vital capacity of the lungs and the tendency to dyspnea.

\section{HISTORICAL}

No attempt will be made to give here a complete review of the literature which relates to the vital capacity of the lungs, but attention may be called to a few important contributions on the subject. In 1846 Hutchinson ${ }^{2}$ reported a study of the relation of the vital capacity to the height in a large series of normal persons. In 1855 Arnold $^{3}$ published an extensive and carefully compiled monograph on the vital

* Submitted for publication April 30, 1917.

* From the Medical Clinic of the Peter Bent Brigham Hospital and the Medical School of Harvard University.

1. Peabody, F. W.: See page 433, this issue.

2. Hutchinson, Jonathan: Med. Chir. Tr., London, 1846, 29.

3. Arnold: Ueber die Athmungsgrösse des Menschen, Heidelberg, 1855. 
capacity in health and disease. He studied the influence of age, sex, height, size and expansion of chest, and habit of life on the vital capacity, and showed that all of these factors may have considerable effect on it. The changes in the vital capacity in a number of pathologic conditions including heart disease are also described by him. Bohr $r^{4}$ in 1907 published his important investigation on the "Mittellage" of the lungs, including determinations of the residual, reserve and complemental air, the total lung volume and the vital capacity. The effects produced on them by changes of position, by exercise, by the inspiration of gases, as well as the variations met with in different persons are discussed in detail. Rubow ${ }^{5}$ measured the vital capacity in a number of patients in connection with his studies on the respiration in heart disease, but his chief interest was the change in the "Mittellage" of the lungs. Bittorf and Forschbach ${ }^{6}$ sturlied the lung volumes in pathologic conditions such as emphysema, heart disease and pleural effusions, and report with other data, the change in the vital capacity. Siebeck $^{7}$ has made similar determinations if the lung volumes, and finds in accord with other investigators a low vital capacity of the lungs in heart disease.

\section{METHOD}

The vital capacity of the lungs is the volume of air which can be expired after the deepest possible inspiration. It was determined in these observations by means of a calibrated recording spirometer designed by Krogh. ${ }^{8}$ The movements of the spirometer with inspiration and expiration are written on the smoked drum of a slowly moving kymograph, and permanent records are obtained from which the volume of the respiration can be measured by the use of a graduated scale, with an accuracy of approximately 10 c.c. (Fig. 1). The subjects sit upright in bed or on a chair, and breathe in and out as deeply as possible through a rubber mouthpiece, the nose being closed by a tight clip. The spirometer was placed on a movable carriage, so that it could be taken to the bedside of patients whom it was not desired to bring to the laboratory (Figs. 2 and 3 ). No corrections were made for temperature, pressure, or water vapor tension.

No particular difficulty was experienced in obtaining satisfactory determinations of the vital capacity. Care was always taken to explain to the patients the desired object, and it was necessary to urge them to breathe as deeply as possible. Strict attention must be paid to this point, for otherwise the volume of the respiration is too low, and does

4. Bohr: Deutsch. Arch. f. klin. Med., 1907, 88, 385.

5. Rubow: Deutsch. Arch. f. klin. Med., 1908, 92, 255.

6. Bittorf and Forschbach: Ztschr. f. klin. Med., 1910, 70, 474.

7. Siebeck: Deutsch. Arch. f. klin. Med., 1910, 100, 204.

8. Krogh: Skandin. Arch. f. Physiol., 1912, 27, 100. 
not represent the true vital capacity. As would be expected, the first attempt was often unsatisfactory, but the second or third attempt, after the subject had become accustomed to the apparatus, and after he appreciated what was required of him, almost invariably gave reliable results. The observations were made rapidly, and usually consumed only from three to five minutes for each person. In a small number of patients satisfactory results could not be obtained. This was either because it was impossible to make them understand what they were

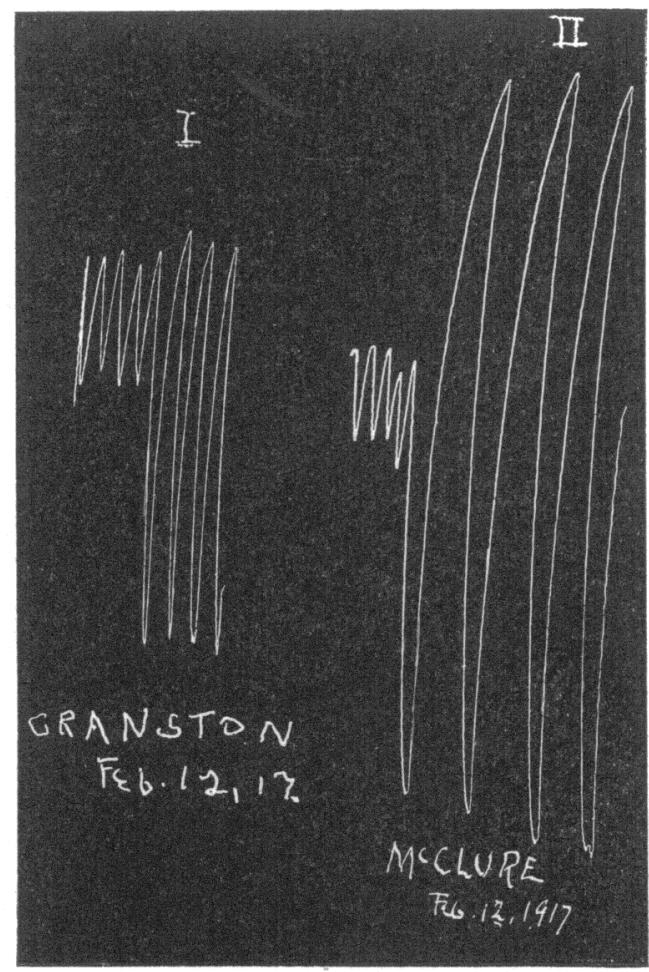

Fig. 1.-Records of vital capacity of the lungs: I. Patient with scvere heart disease beginning to regain compensation: vital capacity was 2,500 c.c. or 52 per cent. of normal standard. II. Normal individual of about the same size; vital capacity was 4,620 c.c. or 96 per cent. of normal standard.

supposed to do, or because they were anwilling to cooperate. In such instances, it was, of course, necessary to discard the records. A little experience enables one to judge accurately as to whether or not the subject is actually breathing as deeply as possible.

Variations in the vital capacity as determined when sitting erect in bed or on a chair were small. Frequent observations have shown that the changes in vital capacity from day to dily in normal persons, and 


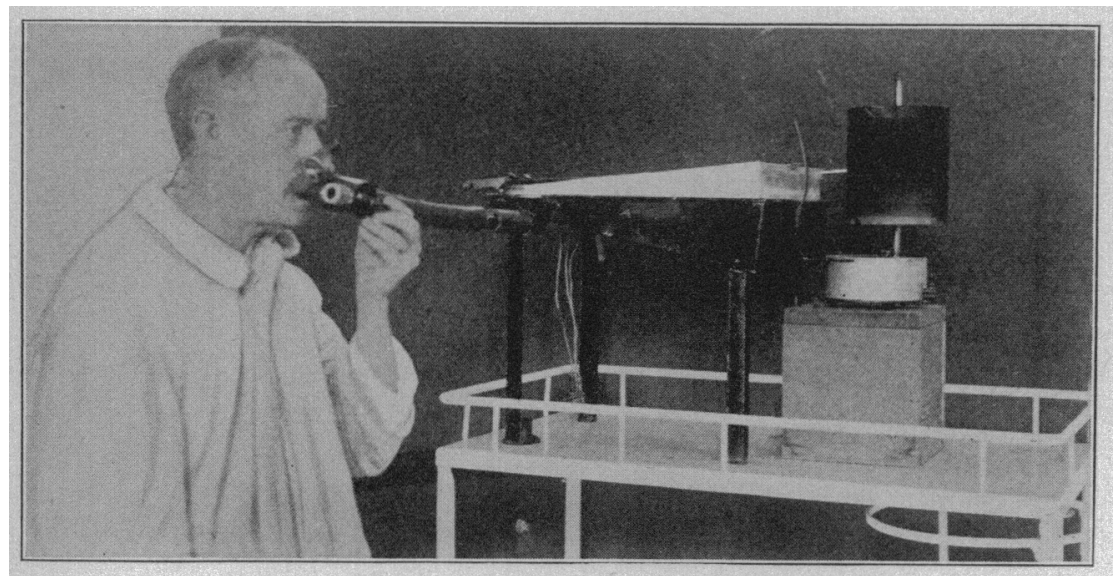

Fig. 2.--Recording spircmcter, showing three-way valve and nose-clip.

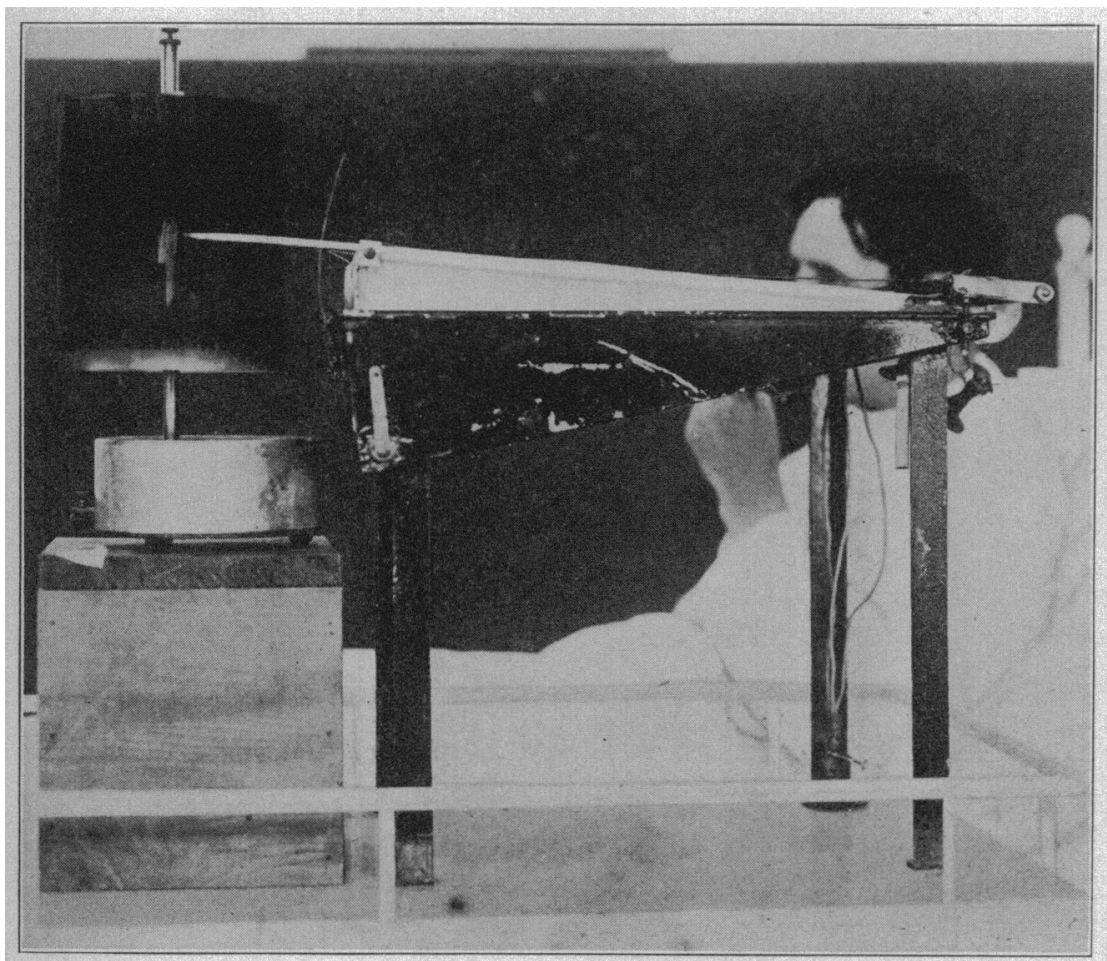

Fig. 3.--Recording spirometer, showing registering of respiration on drum of kymograph. 
in patients whose clinical condition remains constant are practically negligible. The effect of posture was studied in two men. The vital capacity was first measured with the subject standing straight, and then again after he had assumed an exaggerated "slumping," roundshouldered posture in which the thorax acted at a great disadvantage. Such an extreme position is rarely met with, but the maximum difference in the vital capacity under the two conditions was only 590 c.c., or 12 per cent.

In order to simplify the technic of determining the vital capacity we have recently made use of a small portable spirometer of the ordi-

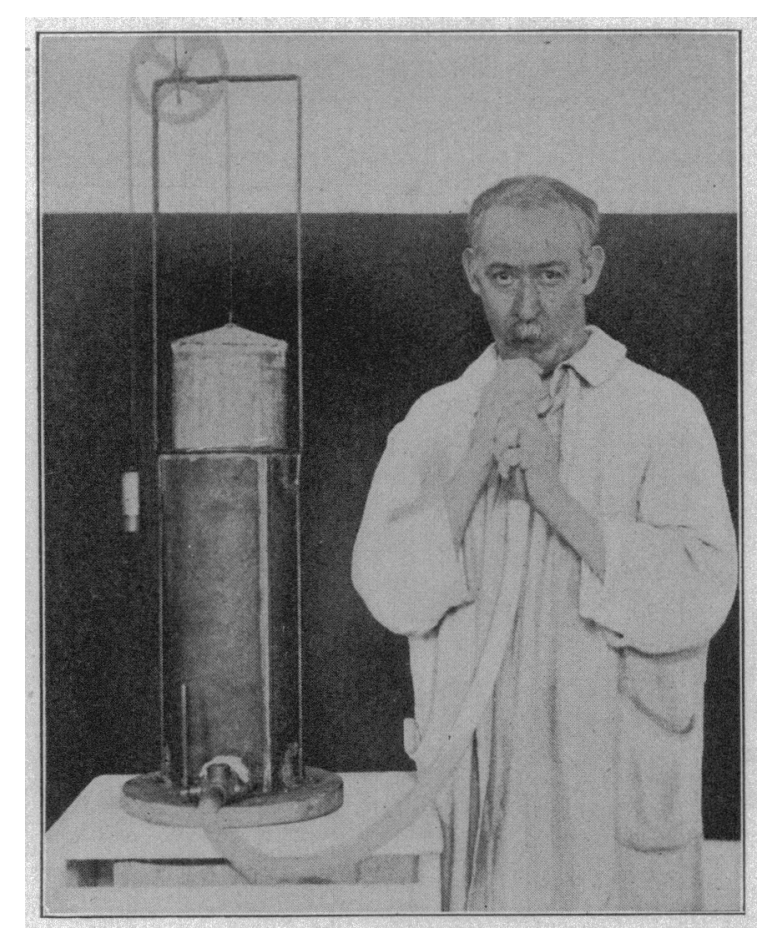

Fig. 4.-Portable spirometer, showing calibrated wheel at the top. This spirometer is made of copper and the bell is of alumirum.

nary type which holds 8 liters of air (Fig. 4). With this apparatus it is not possible to obtain graphic records, but the depth of respiration is measured directly on the calibrated wheel. The chief difference between this spirometer and the recording spirometer is that in the latter the subject breathes in and out several times, and since the lungs and spirometer form a closed system there is no chance for leakage. while with the former the subject takes a deep inspiration and blows it out into the spirometer. With an untrained person it would seem 
possible that some air might be lost before the tube to the spirometer was inserted in the mouth. The two methods have been compared, however, by observations on a series of fifty normal persons and patients, and a strikingly good correspondence between them has been found. The greatest variation in the vital capacity by the two methods was 8 per cent., and in thirty-nine of the fifty persons studied the results agree within 5 per cent. The higher volumes were usually, but not always, obtained with the recording spirometer. It would thus seem that in the clinical study of the vital capacity of the lungs, where the highest degree of accuracy is not to be expected, a well balanced spirometer of the ordinary type may be used satisfactorily.

\section{A. VITAL CAPACITY OF NORMAL ADULTS}

In order to have normal standards of the vital capacity with which to compare the results obtained in disease, a study has been made of 140 healthy persons including physicians, nurses, medical students and a number of ward patients who would be classed as normal from the present point of view. The history of each person was investigated, especially with regard to any tendency to dyspnea, and in many instances a physical examination was made. The subjects ranged between 20 and 50 years of age, but the majority were between 20 and 30 years. They were on the whole a representative group of normal people in every day life. A limited number of observations was made on children, but not enough to give any reliable normal standards. It has, therefore, seemed best not to include any data on the vital capacity of children, either in health or in disease, in the present paper. Since it is generally known that the vital capacity decreases with advancing years, and since a number of the patients studied were over 50 years of age, it would have been better if it had been possible to study more elderly normal persons. Such subjects were, unfortunately, not easy to obtain; but in spite of this the normal standards established appear to be of practical value.

The vital capacity varies normally, as shown by Arnold, with many conditions. Age, sex, height, weight, the size and flexibility of the thorax and physical training may each and all influence it. It was felt to be important, however, in the present clinical study to have as simple a method of standardizing results as possible and, after attempting various ways, it was found that a classification based on sex and height was practical and sufficiently accurate.

In the determination of the normal standards of vital capacity, therefore, the observations on 140 normal persons have been grouped according to sex and for each sex three subgroups have been made on the basis of height. The average normal vital capacity has been determined for each subgroup. Having thus established the normal standards, it has been our custom to refer all subsequent determina- 
tions to these and to express them in percentage of the appropriate normal.

Ninety-six normal males were studied and divided into three groups according to their height. Group I includes those who were $182.5 \mathrm{~cm}$. ( 6 feet) tall or over, and the normal standard computed was 5,100 c.c. Group II consisted of men between $173.5 \mathrm{~cm}$. ( 5 feet, $81 / 2$ inches) and $182.5 \mathrm{~cm}$. ( $6 \mathrm{feet}$ ) tall, and the average vital capacity, which was 4,800 c.c., was taken as the normal. Group III was comprised of persons whose height was between $173.5 \mathrm{~cm}$. ( 5 feet, $81 / 2$ inches) and $159.5 \mathrm{~cm}$. (5 feet, 3 inches). The normal standard of this group was 4,000 c.c. With one exception the vital capacity in all the males examined varied between 86 and 121 per cent. of the normal figure, while 84 per cent. were within 10 per cent. of the normal. The largest vital capacity was 7,180 c.c., or 141 per cent. This was found in a powerful man (G. E. H.) who had recently been a member of the varsity crew, track and football teams in a large university. Four other members of this group had a vital capacity of 6,000 c.c. or over, and all had undergone severe athletic training. Table 1 gives the details of the determinations of vital capacity in the normal males and shows the actual and percentage variations from the standard adopted in each group. It will be noted that in Group I only 63 per cent. of the subjects had a vital capacity within 10 per cent. of the normal. This is explained in part by the small number of observations made in this group, but more particularly by the fact that many of these large mer: were highly trained athletes in whom one would expect to find the vital capacity unusually high. There was a difference of 2,150 c.c. between the highest and the lowest values obtained for the vital capacity in Group I, but if G. E. H., who is $190 \mathrm{~cm}$. (6 feet, 3 inches) tall, be excluded, the difference is only 1,170 c.c. In Group II there was a difference of 1,500 c.c., and in Group III the difference between the highest and the lowest members is 1,630 c.c. There may thus be quitc a variation in the actual vital capacity of normal persons of approximately the same height.

TABle 1.-The Vital Capacity of the Lungs of Normal Males

\begin{tabular}{|c|c|c|c|c|c|c|c|c|c|}
\hline Group & $\begin{array}{l}\text { Number } \\
\text { Studied }\end{array}$ & $\begin{array}{l}\text { Height in } \\
\text { Feet and } \\
\text { Inches }\end{array}$ & $\begin{array}{c}\text { Normal } \\
\text { Vital } \\
\text { Oapac- } \\
\text { ity, } \\
\text { C.c. }\end{array}$ & $\begin{array}{l}\text { Number } \\
\text { Within } \\
10 \text { per } \\
\text { Cent. of } \\
\text { Normal }\end{array}$ & $\begin{array}{c}\text { Highest } \\
\text { Vital } \\
\text { Capac- } \\
\text { ity }\end{array}$ & $\begin{array}{c}\text { Lowest } \\
\text { Vital } \\
\text { Capac- } \\
\text { ity }\end{array}$ & $\begin{array}{c}\text { Highest } \\
\text { per } \\
\text { Cent. }\end{array}$ & $\begin{array}{c}\text { Lowest } \\
\text { per } \\
\text { Cent. }\end{array}$ & $\begin{array}{l}\text { Number } \\
\text { Below } \\
90 \text { per } \\
\text { Cent. of } \\
\text { Normal }\end{array}$ \\
\hline I & 14 & $6^{\prime}+$ & 5,100 & 9 & 7,180 & 5,030 & 141 & 99 & 0 \\
\hline II & 44 & $\begin{array}{c}\text { Over } 5 / 81 / 21 \\
\text { to } 6\end{array}$ & 4,800 & 41 & 5,800 & 4,300 & 121 & 90 & 0 \\
\hline III & 88 & $\begin{array}{l}5 / 3 \prime \prime \text { to } \\
5 / 8 y_{2}^{\prime \prime}\end{array}$ & 4,000 & 31 & 5,080 & 3,450 & 127 & 86 & 1 \\
\hline
\end{tabular}


Special attention is called to the last column in Table 1. It will be seen from this that only one of the ninety-six normal subjects had a vital capacity which was more than 10 per cent. below the appropriate normal standard. This is of particular importance from the standpoint of the present paper, since all of the pathologic conditions which affect the vital capacity produce a decrease of it. For practical purposes, then, the significant fact is the demonstration that healthy males almost invariably have a vital capacity of 90 per cent. or more of the normal standard. A decrease in the vital capacity below 90 per cent. will therefore suggest some pathologic condition.

The most important factor inducing extreme variation in the vital capacity of normal subjects of similar size appears to be athletic training. The average vital capacity of ten highly trained athletes was 120 per cent. of the normal standards. Table 2 shows the actual vital capacity, the percentage of the vital capacity in terms of the normal and a short note as to their athletic experience. The increase of vital capacity had persisted in some of them for several years after strenuous exercise had been last indulged in.

TaBle 2.--The Vital Capacity of the lungs of Ten Athletes

\begin{tabular}{|c|c|c|c|c|}
\hline Subject & $\begin{array}{c}\text { Hejght in } \\
\text { Feet and } \\
\text { Inches }\end{array}$ & $\begin{array}{c}\text { Vital } \\
\text { Capacity, } \\
\text { C.e. }\end{array}$ & $\begin{array}{c}\text { Vital } \\
\text { Capacity, } \\
\text { per Cent. } \\
\text { of } \\
\text { Normal }\end{array}$ & Training \\
\hline G. E. H. & $B 31 / 2 \prime$ & 7,180 & 141 & Track team, football and erew, 4 years \\
\hline P. W. & $6 / 21 / 4$ & 6,100 & 120 & Cross country runner, 4 years \\
\hline P.N. N. & $62^{\prime \prime}$ & 6,100 & 120 & Basket ball and track team, 4 years \\
\hline H. M. R. & $6{ }^{\prime} 1 \frac{1}{\prime \prime \prime}$ & 6,000 & 118 & Crew, much general athletics \\
\hline A. M. G. & $6 / 11 / 4 \prime \prime$ & 6,200 & 122 & Hockey team, football team, crew \\
\hline H. J. & $5 / 111 / 2^{\prime \prime}$ & 5,800 & 121 & Cross country runner \\
\hline F. M. C. & $5 / 11^{\prime \prime}$ & 5,410 & 113 & Football and track teams \\
\hline N. $\mathbf{R}$. & $5 / 111 / 2^{\prime \prime}$ & 5,530 & 115 & Football and track teams \\
\hline F. C. H. & $5 / 101 / 2 "$ & 5,530 & 115 & Cross country runner, 4 years \\
\hline C. R. M. & $560^{\prime \prime}$ & 4,690 & 118 & Football team, 3 years; track team 4 years \\
\hline
\end{tabular}

The women were also subdivided into three groups according to their height. Group I was composed of those who measured over $167 \mathrm{~cm}$. (5 feet, 6 inches) tall, and the average vital capacity was 3,275 c.c. Group II consisted of those who were from $162 \mathrm{~cm}$. ( 5 feet, 4 inches) up to and including $167 \mathrm{~cm}$. ( 5 feet, 6 inches). The normal standard for this group was found to be 3,050 c.c. Group III was made up of persons from $154.5 \mathrm{~cm}$. ( 5 feet, 1 inch) up to and including those who were $162 \mathrm{~cm}$. (5 feet, 4 inches) tall. The standard vital 
capacity for this group was 2,825 c.c. Table 3 gives an analysis of variations from the normal standards in the different groups. Unfortunately, the number of female subjects studied is less than one half the number of males, and this may in part account for the greater percentage of variation from the normal. With a single exception the vital capacities were found to be between 86 and 124 per cent. of the normal. The highest vital capacity, which was 135 per cent., was found in a young woman who had been a student at a school for physical culture. Of the forty-four subjects, thirty had a vital capacity within 10 per cent. of the normal. As was seen to be the case with the normal males, however, only a very small number of females had a vital capacity below 90 per cent. of the normal standards. The lowest vital capacity was 86 per cent., and in but five instances did the vital capacity fall so low as to be between 86 and 90 per cent. of the normal.

Table 3.-The Vital Capacity of the Lungs of Normal Females

\begin{tabular}{|c|c|c|c|c|c|c|c|c|c|}
\hline Group & $\begin{array}{l}\text { Number } \\
\text { Studied }\end{array}$ & $\begin{array}{l}\text { Height in } \\
\text { Feet and } \\
\text { Inches }\end{array}$ & $\begin{array}{c}\text { Normal } \\
\text { Vital } \\
\text { Capac- } \\
\text { ity, } \\
\text { C.c. }\end{array}$ & $\begin{array}{l}\text { Number } \\
\text { Within } \\
10 \text { per } \\
\text { Cent. of } \\
\text { Normal }\end{array}$ & $\begin{array}{c}\text { Highest } \\
\text { Vittal } \\
\text { Capac- } \\
\text { ity }\end{array}$ & $\begin{array}{l}\text { Lowest } \\
\text { Vital } \\
\text { Capac- } \\
\text { ity }\end{array}$ & $\begin{array}{c}\text { Highest } \\
\text { per } \\
\text { Cent. }\end{array}$ & $\begin{array}{c}\text { Lowest } \\
\text { per } \\
\text { Cent. }\end{array}$ & $\begin{array}{l}\text { Number } \\
\text { Below } \\
90 \text { per } \\
\text { Cent. of } \\
\text { Normal }\end{array}$ \\
\hline I & 10 & Over $56^{\prime \prime}$ & 3,275 & 5 & 4,075 & 2,800 & 124 & 80 & 2 \\
\hline II & 13 & $\begin{array}{c}\text { Over } 5^{\prime} 4^{\prime \prime} \\
\text { to } 5^{\prime} 6^{\prime \prime}\end{array}$ & 3,050 & 9 & 3,425 & 2,660 & 112 & 88 & 2 \\
\hline III & 21 & $54^{\prime \prime}$ or less & 2,825 & 16 & 3,820 & 2,500 & 135 & 89 & 1 \\
\hline
\end{tabular}

As far as our figures go, then, one may state fairly definitely that in normal persons the vital capacity is at least 85 per cent., and almost always 90 per cent. or more of the normal standards adopted for each group. In elderly persons a slight decrease from these standards may be expected.

Since it has been proved that the metabolism depends directly on the body surface area, it seemed to be of interest to discover whether some similar relation exists between the vital capacity and the body surface. In a series of nine cases the surface area has been calculated by the linear formula of $\mathrm{Du}$ Bois. ${ }^{9}$ From this limited number of observations it appears that there is a fairly constant relationship between the two, in persons of average build who have led approximately the same type of life as far as exercise goes. In highly trained subjects the ratio of the vital capacity to the surface area is higher than in less athletic persons. Table 4 shows the details of these observations.

9. Du Bois and Du Bois: The Archives Int. Med., 1916, 17, 863. 
Table 4.-The Vital Capacity and Its Relation to Body Surface Area

\begin{tabular}{l|c|c|c|c|c|c}
\hline \hline Subject & $\begin{array}{c}\text { Vital } \\
\text { Capacity, } \\
\text { C.c. }\end{array}$ & $\begin{array}{c}\text { Vital } \\
\text { Capacity, } \\
\text { per Cent. } \\
\text { of } \\
\text { Normal }\end{array}$ & $\begin{array}{c}\text { Surface } \\
\text { Area, } \\
\text { Square } \\
\text { Meter }\end{array}$ & $\begin{array}{c}\text { Vital } \\
\text { Capacity } \\
\text { per } \\
\text { Square } \\
\text { Meter } \\
\text { Surface } \\
\text { Area, } \\
\text { Liters }\end{array}$ & $\begin{array}{c}\text { Vital } \\
\text { Capacity, } \\
\text { Arface } \\
\text { Area }\end{array}$ & Exercise \\
\cline { 2 - 7 } G. P. G. & 4,000 & 100 & 1.57 & 2.55 & 26 & Average \\
D. A. H. & 4,410 & 110 & 1.65 & 2.67 & 27 & Average \\
W. S. B. & 4,710 & 98 & 1.73 & 2.72 & 27 & Average \\
W. S. N. & 4,770 & 99 & 1.77 & 2.70 & 27 & Average \\
F. W. P. & 4,800 & 100 & 1.83 & 2.62 & 26 & Average \\
F. O. H. & 5,360 & 112 & 1.87 & 2.87 & 29 & Quarter mile runner \\
J. A. W. & 5,080 & 106 & 1.87 & 2.72 & 27 & Average \\
L. W. G. & $\mathbf{4 , 5 0 0}$ & 94 & 1.88 & 2.39 & 24 & Average \\
G. E. H. & $\mathbf{7 , 1 8 0}$ & 141 & 2.12 & 3.39 & 34 & Much athletics \\
\hline
\end{tabular}

If $\mathrm{L} . \mathrm{W} . \mathrm{G}$. is excepted, the average vital capacity of the six men who were not athletes corresponded to 2.66 iiters per square meter of body surface. Considerably higher values (2.87 and 3.39 liters) were found in the two athletes. Whether the relationship between the surface area and the vital capacity is actually more constant than is the relationship between height and vital capacity, will only be known after a much larger series of cases has been studied. For the determination of surface area the subject must be weighed stripped, so that unless a considerably higher degree of accuracy were to be obtained, it would be of advantage to maintain the simpler method. It is quite possible that the use of the linear formula for surface area would be valuable when dealing with persons who fall at the limits of two of the height groups. It is in these persons that the greatest deviations from the normal are usually found when height and sex alone are taken into consideration.

\section{B. VITAL CAPACITY OF THE LUNGS IN HEART DISEASE}

It has long been known that the vital capacity of the lungs is frequently decreased in heart disease. The present study, which is based on 224 observations on 124 patients confirms this fact, and shows in a striking manner that the clinical condition of the patient, and more especially the tendency to dyspnea varies very directly with the degree to which the vital capacity is diminished. Many types of heart disease are included, and for the present consideration no attempt has been made to differentiate them. The analysis of the results obtained from this considerable series of determinations is simplified if the patients are classified according to their vital capacity. In connection with 
each group the various features of clinical importance will be discussed, and such deductions drawn as the observations appear to warrant.

Group I consists of cases with a vital capacity of 90 per cent. or more of the normal. There is thus no diminution below the accepted normal standard for the vital capacity. Twenty-five patients fall into this class. Very few of them complained of any symptoms referable to their hearts. Many of them entered the hospital for other diseases, and the cardiac condition was only found in the course of the routine examination. Dyspnea was no more prominent as a symptom in the histories of these patients than it would be found to be in a similar group of normal persons. Twenty-three of the cases in this group were able to work, and the majority without mucb restriction. Only two patients were prevented from working on account of heart disease. One of these (G. A.) had a low grade subacute endocarditis, but showed no dyspnea. The other (I. C.) was a neurotic person who complained constantly of precordial pain. It was impossible to tell whether or not the pain was actually due to cardiac weakness, but he was not encouraged to work. A third patient with mitral disease and evidences of hyperthyroidism (I. M.) gave a history of slight dyspnea on exertion, but she showed no breathlessness after climbing two flights of stairs rapidly with one of us. None of the patients in this group have died.

It is thus evident that cardiac patients with a vital capacity of 90 per cent. or more of the normal are almost invariably in a good state of compensation. They do not suffer from dyspnea after marked exertion, and if, as rarely happens, they are prevented from leading a normal life, this is usually on account of cardiac pain or some other disturbance.

Group II consists of cases in which the vital capacity falls between 70 and 90 per cent. of the normal. Forty-one patients, of whom twenty-four are males and seventeen are females, are included in this group. A history of dyspnea on moderate exertion was commonly given by these patients, but the majority could work, and the others with two possible exceptions, could lead a satisfactory, though some.what restricted life. At the time when the observations on the vital capacity were made, twenty-two were working, four were ready to be discharged from the hospital, and eight were either at home or up and about the wards without symptoms of cardiac insufficiency. It will be well to make brief mention of the clinical condition of the seven remaining patients.

1. F. O., a blacksmith weighing $91 \mathrm{~kg}$., had aortic insufficiency with a rapid heart and rapid respiration. He complained of dyspnea. His vital capacity, July 29 , was 85 per cent. He was extremely nervous and his respiration became 
much slower when he thought he was not observed. History states that he has had dyspnea for four years, but he admits that he has frequently been able to run up four flights of stairs without getting short of breath.

2. V. R. had cardiorenal disease. His vital capacity was 85 per cent. There was a history of dyspnea on exertion before he entered the hospital, but he has shown no tendency to dyspnea since his admission.

3. C. J. H. was an obese man with chronic myocarditis. His vital capacity was 76 per cent. There was history of dyspnea on exertion. There is no dyspnea at present.

4. A. O., a woman, had double mitral disease and auricular fibrillation. Her vital capacity was 74 per cent. There was slight dyspnea on walking about the ward, increased by going up stairs. She has been working as a clerk most of the time for a year since this observation. Her vital capacity is now 73 per cent.

5. I. C. had cardiorenal disease. There is history of dyspnea, but very little evidence of it in the hospital. Her vital capacity was 76 per cent. Six months later she reentered with uremia and marked acidosis and died. It is probable that some of the dyspnea on her first admission can be accounted for by an acidosis.

6 and 7. Two neurotic women, one of them obese, gave a history of dyspnea on exertion but showed little evidence of it when tested by exercising.

In general, then, it may be said that cardiac patients with a vital capacity of between 70 and 90 per cent. of the normal may have well marked heart lesions, but are usually able to lead a satisfactory although somewhat restricted life. About one half of the patients examined were actually at work, and many of the others were perfectly able to do a limited amount of work. One patient in this group showed signs of cardiac insufficiency even while leading a careful life. Only two patients have died, one of uremia and one suddenly, probably of acute cardiac failure or pulmonary cmbolism. On the other hand the members of this group differ from those with a higher vital capacity (Group I) in that almost all of them gave a history of dyspnea on moderate exertion, and have a distinctly limited cardiac reserve. A number of them have had periods of more or less severe cardiac decompensation in which there has been a further drop in the vital capacity. These cases are, therefore, to be regarded as border line cases in which the activities must be somewhat limited, but in which, under favorable circumstances, there is little evidence of cardiac insufficiency.

Group III consists of patients whose vital capacity is only from 40 to 70 per cent. of the normal. Sixty-seven patients, forty-one males and twenty-six females, fall into this class. The characteristic feature of this group is that all its members were in a much less favorable clinical condition than were those who had a higher vital capacity. Dyspnea on even moderate exertion was always noted in the history, and was, indeed, usually the most prominent symptom complained of. Even within the group there was a fairly definite relation between the vital capacity and the clinical condition. Thus all patients with a vital 
capacity of from 40 to 45 per cent. of the normal were in bed. Some of them were slightly dyspneic even when completely at rest, while the others became dyspneic on the least exertion. With a vital capacity of from 45 to 60 per cent. of the normal, patients were rarely dyspneic while in bed, and most of them could walk slowly around the ward without becoming short of breath. A few were living at home and could come to the outdoor department, but they all had to walk slowly and avoided stairs or hills. When the vital capacity was between 60 and 70 per cent. the patients have usually been able to walk fairly comfortably, many could come to the hospital on foot, and could even go upstairs without any special distress. Only five ( 7 per cent.) of the persons in this group were at work when they were examined, and in all cases the work done was very light. Twenty-two (33 per cent.) were up and about the wards without symptoms, or were coming to the outdoor department, and twenty-four (34 per cent.) were still in bed at the time of examination. Eleven patients (17 per cent.) whose vital capacity has been found at some time to fall into this group have died. Only one patient, however, with a vital capacity of over 40 per cent., has died of uncomplicated heart disease in the hospital. E. M., who at one time had a vital capacity of 46 per cent., died four months later of uremia. A. C., with a vital capacity of 48 per cent. on April 7, 1916, died two months later of suffocation from a large aurtic aneurysm. Five patients, all with a vital capacity which was so low that they only just fell into this group, died at home soon after leaving the hospital. Three others died in the hospital after showing a decrease in vital capacity below the limits of this group. Many of the patients who were discharged from the hospital in fairly satisfactory condition, but with a vital capacity of from 40 to 70 per cent., had entered the hospital on account of cardiac decompensation. At the time of admission they usually had a vital capacity which was below 40 per cent., or only slightly above this figure.

Thus cardiac patients with a vital capacity of from 40 to 70 per cent. of the normal are severely handicapped. They practically always suffer from dyspnea even on moderate exertion. Many of them can get about the house or can walk slowly on the street, but there are few whose activities are not very definitely limited, and only a small proportion are able to undertake any form of work. There is a fairly definite relation between the clinical condition of the patient and the vital capacity even within the group, and those with a vital capacity below 45 per cent. are usually forced to remain in bed. Attacks of severe cardiac decompensation occur with considerable frequency in this group of patients, and the mortality among those who have at some time been members of the group is rather high. 
Group IV consists of patients with a vital capacity of 40 per cent. of the normal or less. Twenty-three cases, 11 males and 12 females, were studied in this group. They were all patients whose clinical condition was such that they had to remain in bed, and practically all showed evidences of cardiac insufficiency. Many were definitely dyspneic while absolutely quiet, and the others became short of breath on the slightest exertion. Eight patients whose vital capacity was below 30 per cent., had extreme dyspnea and orthopnea. The lowest vital capacity found was 17 per cent. There was a close relation between the clinical condition and the vital capacity, and as these decompensated patients improved there was a corresponding rise in the vital capacity. Thus G. G., a cardiorenal patient, entered the hospital with a marked orthopnea and a vital capacity of 30 per cent. He improved rapidly, and seven weeks later was at work. At this time his vital capacity had risen to 79 per cent. This is, however, an exceptional instance for only three patients who have at any time fallen into this group have subsequently recovered sufficiently to be able to work. It is of interest, too, that these were all patients undergoing their first break in compensation. The mortality in this group has been high, 61 per cent. of the cases having died. All of the other patients have remained chronic invalids, showing little clinical improvement after weeks of treatment.

Cardiac patients with a vital capacity which is 40 per cent. of the normal or less are usually bedridden and severely decompensated. Many of them have dyspnea even when completely at rest. Patients whose vital capacity falls as low as this during their first period of cardiac insufficiency may improve so much that they are able to return to a fairly normal life, but the occurrence of such a low vital capacity in later attacks of decompensation makes for a distinctly unfavorable prognosis. Few patients who have at any time fallen into this group have shown great clinical improvement, and more than one half have died.

Table 5 shows the mortality statistics, the number of patients showing evidence of marked decompensation and the number of patients working in each group.

It is evident then, in the light of the foregoing statements, that there is a remarkably close relationship between the clinical condition of cardiac patients, particularly as regards their tendency to dyspnea, and the vital capacity of the lungs. If the vital capacity be known, one can state with a considerable degree of accuracy what the functional condition of the patient probably is. It is, however, not at all surprising that certain exceptions to this rule are found, and that in occasional individual instances the determination of the vital capacity gives a misleading conception as to what may be expected of the sub- 
Table 5.-The Relation of the Vital Capacity of the lungs to the Clinical Condition in Patients with Heart Disease*

\begin{tabular}{c|c|c|c|cc}
\hline Group & $\begin{array}{c}\text { Vital Capacity, } \\
\text { per Cent. }\end{array}$ & $\begin{array}{c}\text { Number of } \\
\text { Cases }\end{array}$ & $\begin{array}{c}\text { Mortality, } \\
\text { per Cent. }\end{array}$ & $\begin{array}{c}\text { symptoms } \\
\text { of Decom- } \\
\text { pensation, } \\
\text { per Cent. }\end{array}$ & $\begin{array}{c}\text { Working, } \\
\text { per Oent. }\end{array}$ \\
\hline I & $90+$ & 25 & 0 & 0 & 92 \\
II & 70 to 90 & 41 & 5 & 2 & 54 \\
III & 40 to 70 & 67 & 17 & 39 & 7 \\
IV & Under 40 & 23 & 61 & 100 & 0 \\
\hline
\end{tabular}

* Certain cases were tested several times and, owing to changes in the vital capacity they appear in more than one group. In the "mortality" column they are Included only in the appear in more than one group. In the "mortality" column they are included only in the lowest group into which they fell. "Symptoms of decompensation" indicate dyspnea while at work, and able to continue. Many other patients in Group II were able to work, but they are not included as they were still in the hospital.

ject. When one considers that age, body shape, habits of life, exercise and various other factors all tend to make the normal limits of the vital capacity very broad, it is only remarkable that these exceptions are not met with more frequently, and that such a constant correspondence may be found by what is a comparatively rough clinical test. The explanation of this seems to depend on the fact that the normal variations are usually in the direction of an increase above a certain average, while the pathologic variations are in the direction of a decrease. One type of case which may not conform to the general rule of the relation of clinical condition to average vital capacity is that in which the subject has formerly developed an unusually high normal vital capacity and has subsequently acquired heart disease. In such an instance the pathologic lesion in the heart may be associated with a considerable fall of the actual vital capacity, but the relative vital capacity, when compared to average normal standards, remains high. This brings us to a consideration of the changes in the actual vital capacity in the individual case. The various errors which result from the comparison of the individual to average normal standards are thus excluded, and, as might be expected, the variations found are of even more significance.

In many instances several determinations of the vital capacity of the same case have been made at intervals of days, weeks, or months, over long and short periods. The results of these observations may be rather briefly summarized. A very close relationship has been found to exist between the clinical condition and the vital capacity. Decompensated patients show a low vital capacity which rises as improvement begins, and the degree to which the vital capacity increases corresponds well to the degree of clinical improvement. When the vital capacity remains constant the clinical condition remains unchanged. 
A rapidly rising vital capacity after a period of decompensation leads to a good prognosis, while failure to rise more than a small amount, and the maintenance of a continuously low vital capacity makes the outlook less favorable. Slight changes in the vital capacity of ambulatory cases may be of much significance. This is well illustrated by the case of J. S., a stained glass worker, who has double mitral disease and auricular fibrillation. When in his best physical condition his vital capacity is 2,600 c.c., or 65 per cent. of the normal. At such times he can walk slowly without discomfort, and can do a little light work. On May 1, 1916, he came to the outdoor department, stating that he felt poorly and found that he was getting out of breath more easily than usual. His vital capacity was found to have decreased to 2,000 c.c., or 50 per cent. He was given digitalis and told to go to bed for a week. On May 19, 1916, he reported again, to say that he was as well as before his upset, and his vital capacity had risen to 2,600 c.c.

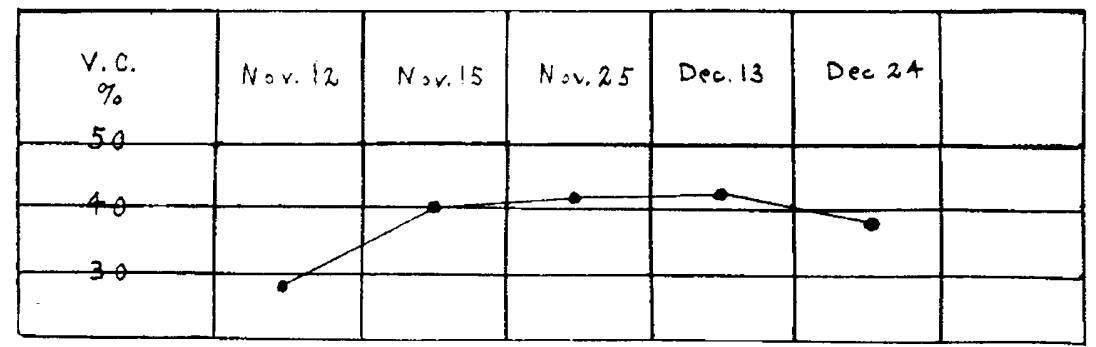

Fig. 5.-M. C. S., showing initial rise in vital capacity after acute cardiac decompensation. Subsequently, the vital capacity remained constantly low. General condition poor.

Figures 5 to 9 show graphically the variations in vital capacity associated with changes in clinical condition. On the basis of the observations as yet made, the impression is quite definite that such charts give a reliable index of the clinical ccurse of the disease. In many ways they are more significant than records of the pulse rate or of the blood pressure, and it is our hope that an extensive routine application of the test of vital capacity may prove to be of distinct clinical value. Medical histories of patients with heart disease abound with vague statements about "dyspnea on exertion," and the increase or decrease of dyspnea, but these are usually only opinions based on the patient's story or on the gross observations of the physician. The importance of such statements would be considerably enhanced if they were confirmed by quantitative graphic methods. Whether, or in how far the determination of the vital capacity will actually fill this need, will only be known after a much larger series of observations than we have yet been able to accumulate has been made. 
Two groups of cases, however, in which the determination of the vital capacity has been of service in correcting false impressions derived from the histories, deserve special mention. Several patients, especially women of rather neurotic temperament, have complained of shortness of breath which was apparently quite out of proportion to the physical findings in the examination of the heart, and the vital capacity has been so high as to afford no explanation for such a tendency to dyspnea. On the suspicion that the symptom was due to nervousness and was not true dyspnea, these subjects have been tested by walking rapidly and by climbing stairs. No abnormal dyspnea has resulted, so that the determination of the vital capacity served to con-

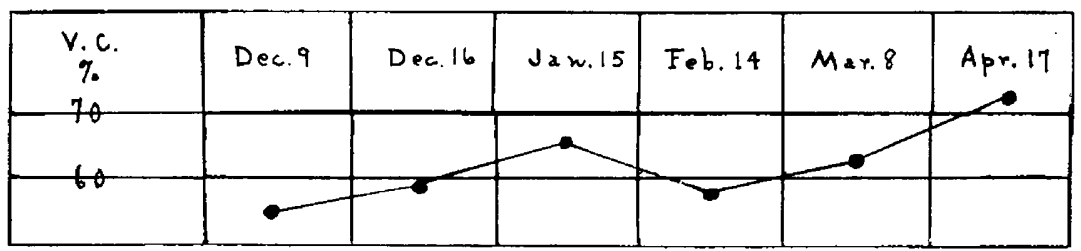

Fig. 6.-W. E. G. The fluctuations in the vital capacity correspond to changes in the clinical condition.

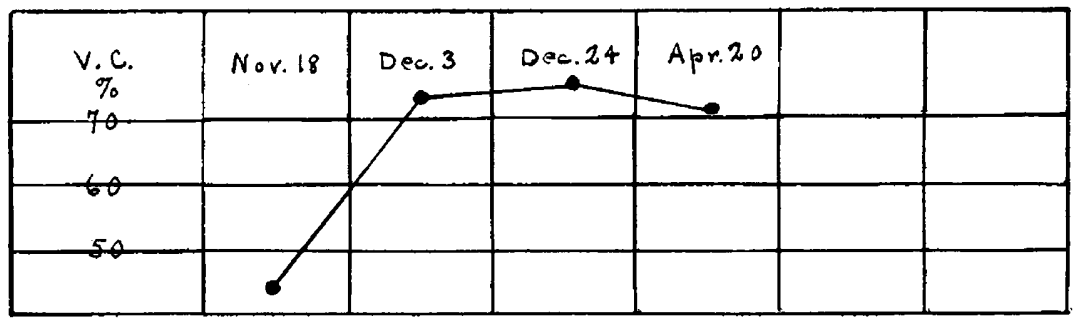

Fig. 7.-I. W. Marked rise in vital capacity, and continued good general condition after acute decompensation.

firm the physical examination, and the history, as given by the patient, could be fairly discounted. On the other hand, a few patients underestimate their respiratory discomfort on exertion. The vital capacity is lower than one would be led to expect from the history, and the lack of dyspnea is difficult to explain. Careful study of such a case, with exercise tests, may demonstrate that the patient's reserve is indeed much less than he has stated, and again the determination of the vital capacity has been a helpful check on the history. In other instances in which the history of dyspnea has seemed out of proportion to the results of physical examination the vital capacity has been low. In these patients the subsequent course has confirmed the value of the history and vital capacity, and has shown that physical examination gave an inadequate conception of the patient's reserve. Thus L. S. 
had a vital capacity of 50 per cent. of the normal, but this was considered to be too low and as not representing her true condition. She never made much clinical improvement, however, and died of cardiac insufficiency some months later.

A careful analysis of the cases of heart disease with a view to finding whether there is any relation between the type of lesion and the decrease of vital capacity revealed little of importance. In general the vital capacity tends to be lower in cases with involvement of the mitral valves than in those in which the aortic valves are affected. This agrees with the common clinical observation that dyspnea is a

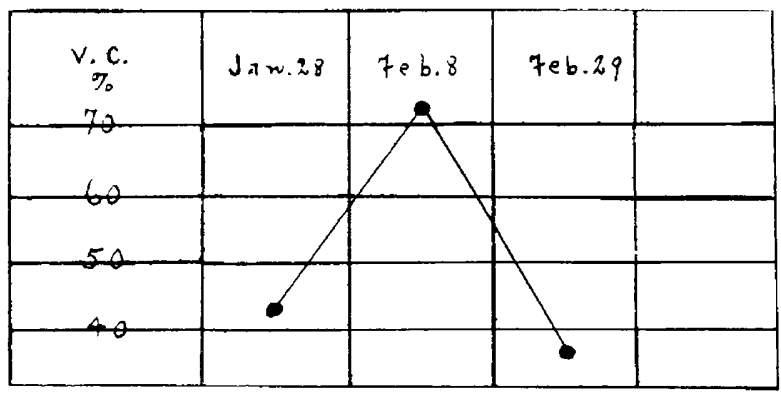

Fig. 8.-M. F. Rise of vital capacity after acute decompensation, and subsequent fall with another attack of cardiac failure.

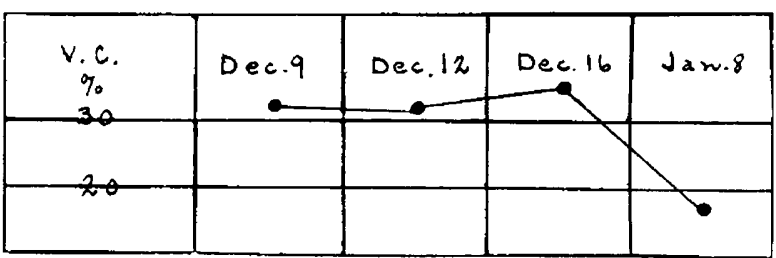

Fig. 9.-F. H. M. Low vital capacity in a patient with marked insufficiency. and further drop just before death.

more prominent symptom in mitral disease than in aortic disease. Beyond this the vital capacity of the lungs seems to depend on the degree of cardiac efficiency; on the severity of the lesion, rather than on the type of lesion.

Cause of the Decrease of Vital Capacity in Heart Disease.-Since the vital capacity of the lungs is the volume of air which can be expired after the deepest possible inspiration, it is evident that any condition which limits the movements of the lungs may be a factor in decreasing the vital capacity. In patients with heart disease a great variety of such conditions may be found. Some of these affect the movement of the chest wall and prevent a normal expansion of the thoracic cavity. Weakness of the intercostal muscles, rigidity of the 
bony framework or ankylosis of the costal joints may act in this way. Alterations in the lung tissue itself may cause a diminution in its elasticity, as is seen in emphysema. Accumulations of fluid in the pleural cavities prevent the normal expansion of the lungs, and great cardiac hypertrophy, pericardial effusion or mediastinal tumors may produce a similar result. The normal inspiratory depression of the diaphragm is interfered with by intrathoracic conditions, which make it assume a flattened position even during quiet respiration, and by intra-abdominal conditions which push it upward. Hepatic enlargement, tympanites and ascites are examples of such conditions. Fluid within the bronchi and smaller air passages may prevent the entrance of air into considerable portions of the lung. This is, of course, frequently found in the dependent parts of the lungs in severely decompensated patients. The effect produced by a generalized bronchitis is not wholly clear from the results which we have as yet accumulated. The decrease in vital capacity associated with this condition is frequently much less than one would expect, and observations suggest that the intense dyspnea sometimes occurring in cardiac patients who acquire an acute bronchitis is largely dependent on some factor other than a change in the vital capacity.

In many cases, and particularly in acutely decompensated patients, conditions such as those just mentioned appear to account for the decrease in the vital capacity of the lungs in a wholly satisfactory manner. In other instances, especially where the examination of the heart gives little evidence of insufficiency, and where dyspnea is only experienced on moderate exertion, all of these factors may be absent, and yet the vital capacity may be low enough to fully explain the history of shortness of breath. The cause of the low vital capacity in such cases is not absolutely certain, but the work of Siebeck ${ }^{i}$ on the determination of the lung volumes in heart disease bears on the question and suggests that the decrease in vital capacity may be due to an overfilling or engorgement of the pulmonary vessels, and a consequent diminution of the elasticity of the lungs. If this is proved to be true it would signify that the determinations of vital capacity may give direct evidence as to the state of the pulmonary circulation. Such information would be of great value in the study of cardiac insufficiency. Other methods of examination bear chiefly on the greater circulation, and disturbances in the pulmonary circuit are only recognizable when of sufficient grade to cause the passage of fluid out of the vessels into the air spaces and the production of râles.

Experiments have been made to determine whether the decrease in the vital capacity in heart disease is apparent rather than real, and whether the inability to breathe deeply might depend on the rapid rate 
of respiration. This would be the case, for instance, if an imperative stimulus to inspire should arise before the end of complete expiration. That this is, however, rarely, if ever, of importance is shown by the fact that patients with a low vital capacity may be able to hold their breath for several seconds at the end of either complete inspiration or of complete expiration.

\section{DISCUSSION}

The observations described above indicate that in patients with heart disease there is a close relationship between dyspnea and the vital capacity of the lungs. Thus, in general, patients with a vital capacity of 90 per cent. or more of the normal standard adopted for their sex and height have little or no abnormal tendency to dyspnea. Patients with a vital capacity of from 70 to 90 per cent. of the normal become short of breath on unusual exertion and must lead a restricted life, although many of them can do light work. Patients with a vital capacity of from 40 to 70 per cent. of the normal are much more limited in their activities. They become dyspneic on moderate or slight exertion, are rarely able to work and frequently suffer from cardiac decompensation. Those with a vital capacity of less than 40 per cent. of the normal are decompensated patients, usually confined to bed, and the mortality in this group is high. There is, moreover, a close correspondence in the individual case between changes in the vital capacity and variations in the tendency to dyspnea. In stages of decompensation the vital capacity falls, and with recovery the vital capacity rises. Indeed, comparatively slight changes in the patient's physical condition may manifest themselves in changes in the vital capacity. These facts confirm the evidence in a former paper regarding the importance of the decrease in vital capacity as a factor in the production of dyspnea in heart disease. Various obvious causes of decrease in the vital capacity, such as pleural effusion, emphysema and ascites, have been mentioned and the suggestion has been made that an important factor may be the distention of the pulmonary vessels owing to cardiac insufficiency. If this be true, then the determination of the vital capacity of the lungs may be of value as an early sign of cardiac weakness.

The importance of these observations depends on the relation between the vital capacity and the clinical condition of the patient. It is true that decrease in the vital capacity is only directly associated with a single symptom of heart disease. But this symptom, dyspnea, is a remarkably common one, and the intensity of dyspnea or of the tendency to dyspnea usually follows so closely the clinical course of the disease that it is not infrequently considered a guide to the con- 
dition of the patient. It is, in a way, an index of the cardiac reserve, and thus, indirectly, a measurement of the efficiency of the heart. The degree of dyspnea and the tendency to dyspnea are, however, peculiarly difficult to describe accurately or to classify systematically, so that any objective method which will give even approximately exact evidence with regard to dyspnea merits serious consideration by clinicians. The determination of the vital capacity of the lungs, while lacking in absolute quantitative accuracy, is a simple proceeding which appears to do this. The changes in the vital capacity throw interesting light on the course, and often on the prognosis of the disease.

It is important, however, to appreciate that changes in the vital capacity of the lungs are an index of the clinical condition only in so far as the cardiac weakness manifests itself chiefly by causing dyspnea. This is very frequently, but not at all invariably the case. Certain patients with heart disease are restricted in their activities not by becoming dyspneic, but by the occurrence of palpitation or by pain. The vital capacity of the lungs has no direct connection with palpitation or pain, and therefore, in cases in which these are the presenting symptoms, it does not necessarily bear any relation to the clinical condition of the patient.

\section{VITAL CAPACITY OF THE LUNGS IN VARIOUS OTHER DISEASES}

Although the present study was directed chiefly to a consideration of the vital capacity of the lungs in heart disease, a comparatively large number of observations has been made in other clinical conditions. In some of these a tendency to dyspnea is a common symptom, and in others it is not. Such a series of observations is, of course, of great importance, for it shows in how far the various factors which decrease the vital capacity affect the production of dyspnea in conditions other than heart disease, and also in how far general muscular weakness is an element in causing a decrease of the vital capacity of the lungs. A brief summary of the results obtained in each disease is given below.

Bronchial Asthma.-Many patients with chronic asthma develop an emphysema, and associated with this they are subject to various degrees of dyspnea on exertion. It is thus not surprising to find that the vital capacity may be below normal even in the period between attacks. During the asthmatic attacks the vital capacity becomes much lower. Seven observations on six patients when they were in their best condition between attacks showed the vital capacity to range between 65 per cent. and 122 per cent. of the normal. In only one case was it below 85 per cent. This patient had suffered from asthma for twenty years, became dyspneic easily, and had never been able to do a full day's work. Four patients were tested soon after acute attacks 
or at a time when many characteristic râles were present in the lungs. In three the vital capacity was 56,60 and 85 per cent. The fourth, who stated that she had no dyspnea between attacks, had a vital capacity of 102 per cent. in spite of the presence of a few râles. For obvious reasons it was almost impossible to obtain records of the vital capacity during severe attacks of asthma.

Acute Bronchitis.-In three severe cases of acute bronchitis the vital capacity has not been diminished more than 10 per cent. In a fourth case of uncomplicated bronchitis in a young woman of 24 years, the vital capacity dropped to 76 per cent. of the normal. Objectively, she showed little evidence of dyspnea, but she complained of dyspnea. Several patients with cardiac disease have entered the hospital with extreme dyspnea and a well marked bronchitis. They have, however, not shown a decrease of vital capacity of more than 10 per cent. below the normal figure, and recovery has been rapid. It seems probable that the dyspnea in these cases was due to bronchitis and not to true cardiac decompensation.

Pleural Effusions.-This group includes cases with hydrothorax, pneumothorax, hemothorax, empyema and one instance of carcinoma of the pleura associated with a large pleural effusion. Nine patients have been studied. The vital capacity has been found to vary between 74 and 42 per cent. of the normal. In general the vital capacity seems to depend on the amount of fluid or air in the pleural cavity, and there is a close relationship between the decrease in the vital capacity and the tendency to dyspnea. Some of the patients were extremely sick, and their muscular weakness is probably a factor in lowering the vital capacity.

One patient (T. W.) with a pleural effusion that seemed to fill the left side of his chest, so that the lung was almost completely collapsed, har a vital capacity on two successive days of 48 and 49 per cent. Immediately after thoracentesis, with the removal of 2,200 c.c. of fluid, his vital capacity was still 46 per cent. On the two following days it had risen to 69 and 68 per cent., and three weeks later it was 74 per cent. At this time he could walk about the ward without any sensation of dyspnea, but there were still signs of fluid below the angle of the scapula on the left.

Pneumonia.-No records were obtained on patients during the course of the disease as the pain from the pleuritis makes it impossible for them to take a deep breath. In five convalescent cases, only one of which still showed evidence of pulmonary involvement, the vital capacity was between 71 and 114 per cent. The vital capacity was below normal in three cases, and in them general weakness, persisting after an acute infection, must be taken into consideration. 
Cirrhosis of the Liver. - A patient with extensive edema and marked ascites had a vital capacity of 35 per cent. Another advanced case, with great ascites had a vital capacity of 35 per cent., rising to 61 per cent. after the removal of 10 liters of fluid. A man with early cirrhosis of the liver, without ascites, but giving a history of dyspnea on going upstairs (perhaps due to a weak heart) had a vital capacity of 85 per cent. Mechanical interference with the movements of the lungs is the essential factor causing dyspnea in these cases.

Ncphritis. - In eight cases of acute nephritis without history of dyspnea, there was no decrease below the normal of the vital capacity. One other patient with acute nephritis, an Arab, had a vital capacity of 71 per cent., but it was impossible to get entirely satisfactory cooperation on the part of the patient, and it is doubtful whether he was breathing as deeply as he could.

In patients with chronic nephritis there is, of course, very frequently an associated involvement of the heart, but it is difficult to say in any individual case exactly how important this feature is. A considerable number of cases of chronic nephritis have been examined, some of them with and some of them without cardiac lesions. In those without evidence of heart disease, and without a history of dyspnea, the vital capacity was high and usually within the normal limits. In the cardiorenal cases, on the other hand, dyspnea was one of the prominent symptoms, and the vital capacity was usually decreased in proportion to the intensity of the dyspnea.

Certain patients with advanced renal disease have a much higher degree of dyspnea than can be explained on the basis of the decrease in the vital capacity alone. Not infrequentiy an examination of the blood or alveolar air will show a decreased carbon dioxid content. The dyspnea depends in part on an acidosis, and it may be relieved by alkali therapy.

Hyperthyroidism.--Dyspnea on exertion is one of the commonest symptoms complained of by patients with Graves' disease. This may sometimes be the result of nervousness, but it is usually an indication of cardiac weakness. Seven patients were tested, and the vital capacity was above 80 per cent. in five, while in two it was between 67 and 75 per cent. In all the decrease in vital capacity corresponded to the degree of the tendency to dyspnea.

Anemia.-Patients with anemia frequentiy suffer from dyspnea. Careful analysis of our series of cases, however, showed that weakness was a more common symptom, and in only five out of fourteen patients was a definite history of true dyspnea on exertion obtained. Eleven of these were typical cases of pernicious anemia, two were probably due to carcinoma, and one was secondary to infection with 
Dibothriocephalus latus. In eleven cases the vital capacity was 80 per cent. or more, and in two others it was between 70 and 80 per cent. A very emaciated man of 66 years, who was considered to have advanced abdominal cancer, had a vital capacity of 65 per cent. The relation between the tendency to dyspnea and the decrease in vital capacity was not such as to make one consider that the latter was the chief factor in causing dyspnea. It seems more probable that dyspnea in anemia is due directly to the low hemoglobin content of the blood and is of a different mechanism from that in the other conditions which have been considered.

Diseases Unassociated with Dyspnea.-In contrast to the foregoing conditions, thirty patients have been tested who were in the hospital for conditions which are usually not associated with dyspnea. None of the mechanical factors which limit the movements of the lungs were present, and in them the effect of general debility and weakness could be studied. This group of cases includes acute and chronic arthritis, hemiplegia, diabetes, gastro-intestinal diseases, tabes, convalescents from acute infections such as typhoid fever and a number of persons in the surgical wards for slight operations. In twenty-four of the thirty cases the vital capacity was 85 per cent. or more, and in eighteen it was 90 per cent. or more of the normal. It will be well to make brief note of the six patients with vital capacity below 85 per cent. Three of them were diabetics. An emaciated decrepid old man of 69 years had a vital capacity of 63 per cent.; a second patient, so weak that he had to be helped up stairs, had a vital capacity of 76 per cent., and a third patient with diabetes for a year had a vital capacity of 68 per cent., but it was felt that his record was not satisfactory, and did not represent his true vital capacity. A woman, aged 66 years, who probably had peritoneal adhesions, complained of marked dyspnea on exertion and had a vital capacity of 78 per cent. A short man, aged 58, who had vertigo of an unknown cause, but who gave no history of dyspnea, had a vital capacity of 78 per cent. Finally, a young man of 23 years with a chronic synovitis of the knees was found to have a vital capacity of 84 per cent. of the normal. This subject was in bed for practically one year, and had then been on crutches for one year. He has used a cane up to within a week of the time he was tested, and stated that he still became short of breath on hurrying or on going up stairs.

As far as this comparatively small series of patients goes, then, it shows that in the ordinary cases in which dyspnea is not a prominent symptom, the vital capacity is usually within the normal limits. General weakness and debility may account for a slight decrease in the vital capacity, but unless the weakness is extreme it usually does not 
cause the vital capacity to drop more than 5 or 10 per cent. below the normal limits. Several patients in whom the vital capacity was below normal were over 50 years of age, and the decrease is in part explained by the normal fall in the vital capacity with advancing years.

\section{SUMMARY}

Determinations of the vital capacity of the lungs in a large number of healthy persons has made it possible to establish average normal standards for groups of individuals of different sex and height. When compared to the proper standard the vital capacity of healthy persons very rarely falls below 90 per cent. of the normal standard, although it may rise considerably above the normal.

Observations on patients with heart disease show that there is a close relation between decrease in vital capacity and the tendency to dyspnea. Compensated patients, who do not complain of dyspnea on exertion, have a normal vital capacity. Patients with more serious disease, in whom dyspnea is a prominent symptom, have a low vital capacity, and the decrease in vital capacity runs parallel to the clinical condition. Changes in the clinical condition are usually associated with changes in the vital capacity. As a patient improves, his vital capacity tends to rise, and as he becomes worse, it tends to fall. Determinations of the vital capacity in cases of cardiac disease are often of practical value as they give quantitative information as to the tendency to dyspnea, and thus, indirectly, as to the clinical condition and the reserve power of the patient.

In various other diseases in which mechanical conditions interfere with the movements of the lungs, the tendency to dyspnea corresponds closely to the decrease in the vital capacity. This is, however, apparently not true of the anemias. In diseases in which dyspnea is not a prominent symptom the vital capacity is usually within the normal limits, although general weakness and old age may cause a slight decrease. 